\title{
Trends in Diagnosis and Surgical Management of Patients with Perforated Peptic Ulcer
}

\author{
Kenneth Thorsen • Tom B. Glomsaker • \\ Andreas von Meer $\cdot$ Kjetil Søreide $\cdot$ Jon Arne Søreide
}

Received: 21 December 2010 / Accepted: 27 February 2011 /Published online: 13 May 2011

(C) 2011 The Author(s). This article is published with open access at Springerlink.com

\begin{abstract}
Introduction While the laparoscopic treatment of perforated peptic ulcers (PPU) has been shown to be feasible and safe, its implementation into routine clinical practice has been slow. Only a few studies have evaluated its overall utility. The aim of this study was to investigate changes in surgical management of PPU and associated outcomes.

Material and Methods The study was a retrospective, single institution, population-based review of all patients undergoing surgery for PPU between 2003 and 2009. Patient demographics, diagnostic evaluation, management, and outcomes were evaluated.

Results Included were 114 patients with a median age of 67 years (range, 20-100). Women comprised 59\% and were older $(p<0.001)$, had more comorbidities $(p=0.002)$, and had a higher Boey risk score $(p=0.036)$ compared to men. Perforation location was gastric/pyloric in $72 \%$ and duodenal in $28 \%$ of patients. Pneumoperitoneum was diagnosed by plain abdominal $\mathrm{x}$-ray in 30 of 41 patients $(75 \%)$ and by abdominal computerized tomography (CT) in 76 of 77 patients $(98 \% ; p<0.001)$. Laparoscopic treatment was initiated in 48 patients $(42 \%)$ and completed in 36 patients $(75 \%$ of attempted cases). Laparoscopic treatment rate increased from $7 \%$ to $46 \%$ during the study period $(p=0.02)$. Median operation time was shorter in patients treated via laparotomy $(70 \mathrm{~min})$ compared to laparoscopy $(82 \mathrm{~min})$ and those converted from laparoscopy to laparotomy (105 min; $p=0.017$ ). Postoperative complications occurred in 56 patients (49\%). Overall 30-day postoperative mortality was $16 \%$. No statistically significant differences were found in morbidity and mortality between open versus laparoscopic repair.

Conclusion This study demonstrates an increased use of CT as the primary diagnostic tool for PPU and of laparoscopic repair in its surgical treatment. These changes in management are not associated with altered outcomes.
\end{abstract}

Keywords Peptic ulcer $\cdot$ Perforation $\cdot$ Diagnosis $\cdot$ Surgery Laparoscopy

K. Thorsen · T. B. Glomsaker · K. Søreide · J. A. Søreide $(\bowtie)$ Division of Gastroenterologic Surgery, Department of Surgery, Stavanger University Hospital, 4068 Stavanger, Norway e-mail: jon.soreide@kir.uib.no

A. von Meer

Department of Radiology, Stavanger University Hospital, Stavanger, Norway

K. Søreide · J. A. Søreide Department of Surgical Sciences, University of Bergen, Bergen, Norway

\section{Introduction}

In spite of improved understanding of the multifactorial etiology of peptic ulcer disease (PUD),${ }^{1-3}$ life-threatening complications including acute hemorrhage or perforation occur in a considerable proportion of patients. The mortality rate ranges from $10-40 \%$ among patients with perforation, ${ }^{4-6}$ and immediate surgery is the treatment of choice in most patients with suspected perforated peptic ulcer (PPU). ${ }^{4}$

Laparoscopic surgical management of PPU was first reported by Nathanson ${ }^{7}$ and coworkers in 1990 and has gained increasing attention in recent decades. Preliminary early reports, ${ }^{8-10}$ including randomized controlled trials, ${ }^{11}$ data provided from a recent meta-analysis, ${ }^{12}$ and 
other publications, ${ }^{13,14}$ have strengthened the scientific evidence supporting this approach. While laparoscopy is regarded as feasible and safe, it is hindered from integration into routine practice by the lack of surgeons capable of this technique on a 24-h basis in all hospitals caring for patients with PPU. A recent report from Denmark reported that only $6 \%$ of patients with PPU were treated laparoscopically. ${ }^{15}$

The aim of this audit was to evaluate the surgical management and outcome of consecutive patients diagnosed with PPU during a time period when the laparoscopic treatment of PPU was introduced and available in a busy surgical department covering a defined population in Norway.

\section{Materials and Methods}

All consecutive patients diagnosed with perforated gastric ulcer (GU) or duodenal ulcer (DU) between January 2003 and December 2009 were identified from the hospital's prospective administrative electronic database using pertinent ICD-9 and ICD-10 codes (K25.1, K25.2, K25.5, $\mathrm{K} 25.6$, and K26.1, K26.2, K26.5, K26.6). Additional searches were performed using appropriate surgical procedure codes (JDA60 Gastroraphy, JDA61 Laparoscopic gastroraphy, JDH70 Duodenoraphy, and JDH71 Laparoscopic duodenoraphy) to enable a complete identification of all patients. Our hospital is the only hospital in the region which has a population of 320,000 .

Included in the study were patients with perforated GU or DU who underwent surgical treatment. Patients treated medically/conservatively were excluded, as were patients diagnosed at autopsy. Demographics and clinical data were obtained from hospital records, surgical notes, and other sources as needed.

American Society of Anesthesiologists (ASA) classification, as judged and recorded by the responsible anesthetist at surgery, was retrieved from perioperative forms. Each patient was retrospectively classified according to the Boey score ${ }^{16}$ based on available information on the three criteria: (a) shock at admission (systolic blood pressure $<90 \mathrm{mmHg}$ ), (b) severe medical illness (ASA III-V), and (c) delayed presentation (duration of symptoms $>24 \mathrm{~h}$ ). For this scoring system, the patient is given one point for each positive criterion, with possible scores of $0-3$. Severity of complications was retrospectively classified according to the Dindo-Clavien criteria. ${ }^{17}$

A unique personal 11-digit identification number of all citizens in our country enabled complete follow-up data with regard to survival. Data without case-sensitive personal identification were recorded in an appropriately designed database.
Study Ethics

The study was as approved as a quality control assurance according to general guidelines provided by the Regional Ethics Committee.

\section{Statistical Analysis}

PASW Statistics 18.0 for Mac (SPSS Inc., Chicago, IL) was used for statistical analysis. A nonparametric distribution was assumed, and descriptive analysis was performed using Chi-square or Fisher's exact test where appropriate for dichotomous data, and Kruskal-Wallis or Mann-Whitney $U$ test for continuous data, where applicable. A $p$ value $<0.05$ was considered statistically significant.

\section{Results}

Between 2003 and 2009, 114 consecutive patients (67 females (59\%) and 47 males (41\%)) were surgically treated for PPU at our hospital. The calculated average annual incidence of surgically treated patients with PUP was 5/100,000.

Table 1 reports patient characteristics. While a significantly higher proportion of females ( $p=0.002$ ) was diagnosed with additional diseases and comorbidity, the ASA classification was similar for both genders (Table 1). Concomitant diseases included 49 patients (43\%) with cardiovascular disease, $20(18 \%)$ with a current or previous diagnosis of cancer, $17(15 \%)$ with chronic pulmonary disease, and 15 (13\%) with an autoimmune disorder. In addition, 52 patients (46\%) had either other concomitant diseases not specifically classified or a combination of several diagnoses.

\section{Risk Factors}

Fifty-nine patients (52\%) smoked daily. Ongoing medical treatment was recorded in a significant proportion of patients, including aspirin in 26 patients $(23 \%)$, nonsteroidal anti-inflammatory drugs in $23(20 \%)$, and systemic steroids in $9(8 \%)$.

Thirty patients $(26 \%)$ had a Boey score of 2 or 3 , indicating increased risk of unfavorable outcome. The Boey score profile was significantly lower in females compared to males $(p=0.036)$. At admission, clinical evidence of peritonitis was present in 76 patients $(66 \%)$, with no differences according to gender.

\section{Diagnosis and Preoperative Imaging}

As shown in Fig. 1, plain abdominal imaging was more or less replaced by abdominal computerized tomography $(\mathrm{CT})$ as the imaging modality of choice during the study period. Forty- 
Table 1 Patient characteristics

\begin{tabular}{llll}
\hline Variable & Males $47(41 \%)$ & Females $67(59 \%)$ & Total $114(100 \%)$ \\
\hline Age, years (median, range) & $61(20-90)$ & $73(29-100)$ & $67(20-100)$ \\
Age $>60$ years & $26(55 \%)$ & $52(78 \%)$ & $78(68 \%)$ \\
Comorbidity ${ }^{\mathrm{a}}$ & $32(68 \%)$ & $61(91 \%)$ & $93(82 \%)$ \\
Smoking & $25(78 \%)$ & $34(56 \%)$ & $59(52 \%)$ \\
ASA & & & 0.012 \\
1 & - & - & $2(2 \%)$ \\
2 & - & $2(3 \%)$ & $71(62 \%)$ \\
3 & $31(66 \%)$ & $40(60 \%)$ & $37(33 \%)$ \\
4 & $15(32 \%)$ & $22(33 \%)$ & $4(3 \%)$ \\
5 & $1(2 \%)$ & $3(5 \%)$ & 0.002 \\
Boey score & & & $26(23 \%)$ \\
0 & $17(36 \%)$ & $9(13 \%)$ & $58(51 \%)$ \\
1 & $20(43 \%)$ & $38(57 \%)$ & $25(22 \%)$ \\
2 & $9(19 \%)$ & $16(24 \%)$ & $5(4 \%)$ \\
3 & $1(2 \%)$ & $4(6 \%)$ & $36(32 \%)$ \\
Surgery completed laparoscopically & $11(34 \%)$ & $25(37 \%)$ & $5(48 \%)$ \\
Complications & $21(45 \%)$ & $34(51 \%)$ & $18(16 \%)$ \\
Mortality & $5(11 \%)$ & $13(19 \%)$ & $8(6-17)$ \\
LOS, days (median, IQR) & $7(6-19)$ & $8.5(5-16)$ & 0.036 \\
\hline
\end{tabular}

$A S A$ American Society of Anesthesiology score, LOS length of stay, IQR interquartile range

${ }^{a}$ Defined as current concomitant diseases recorded at hospital admission

${ }^{\mathrm{b}}$ Defined according to the Dindo-Clavien criteria ${ }^{17}$

${ }^{\mathrm{c}}$ Defined as death within 30 days

one patients (36\%) underwent plain abdominal x-ray, and pneumoperitoneum was diagnosed in $30(75 \%)$ of these patients. Diagnosis and surgery were delayed in six patients with initial negative plain abdominal x-ray. Abdominal CT, usually low dosage, was done in 60 patients $(68 \%)$, with pneumoperitoneum diagnosed in 59 (99\%). In 91 patients

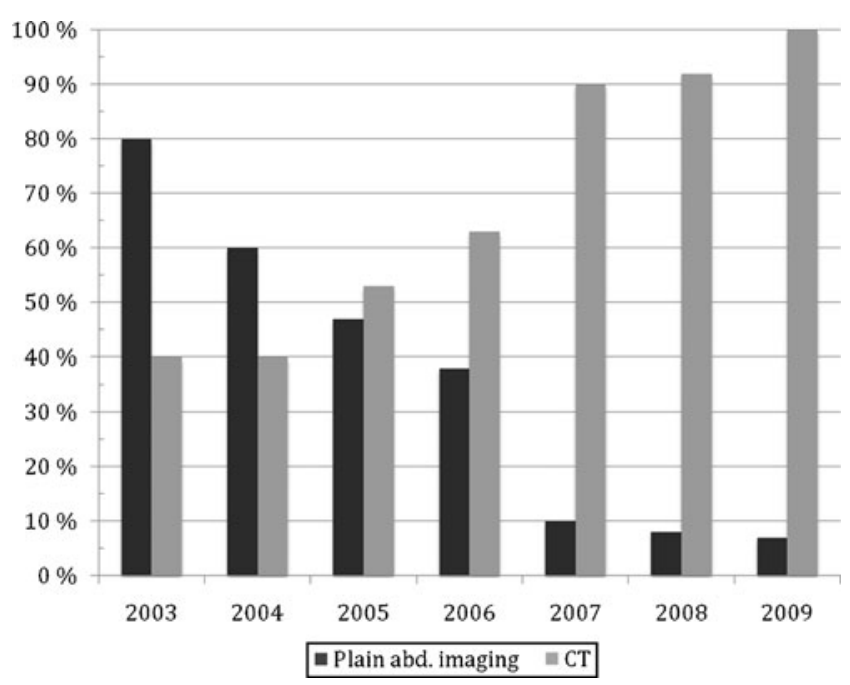

Fig. 1 Changes in preoperative abdominal imaging during the study period
(80\%) with pneumperitoneum diagnosed radiographically, visceral perforation was already suspected based on history and clinical examination. On the other hand, 23 patients (20\%) had pneumoperitoneum diagnosed without clinical suspicion of visceral perforation.

\section{Perforations}

Perforations were localized to the prepyloric region in 46 patients $(40 \%)$, duodenum in $32(28 \%)$, pylorus in 15 $(13 \%)$, and antrum in $6(5 \%)$. In the remaining 15 patients (14\%), perforation was either in the corpus of the stomach or not otherwise specified. No differences between genders were observed. In 16 patients (14\%), a combination of ulcer bleeding and perforation was encountered.

\section{Surgery}

A gastro- or duodenoraphy was performed in 106 patients (93\%), including tegmentation in $93(82 \%)$. Pre- and postoperative antibiotics were given to $98(86 \%)$ and 101 (89\%) patients, respectively.

Laparoscopy was initiated in 48 patients (42\%), and the surgical treatment (i.e., raphy) was completed laparoscopically in $36(75 \%)$ of these patients; thus, $32 \%$ of the total 
114 patients were treated laparoscopically. In three patients, a Billroth I or a Billroth II resection was done, of whom one patient was eventually surgically treated for a second PPU. As the study period progressed, the use of laparoscopy increased significantly ( $p=0.002$; Fig. 2 ).

\section{Operative Time}

Median time from hospital admission to surgery was $6.2 \mathrm{~h}$ (interquartile range (IQR), 4.4-16.1). Median operation time was $80 \mathrm{~min}$ (IQR, 60-106), and median length of postoperative stay (LOS) was 8 days (IQR, 6-17).

\section{Morbidity and Mortality}

The 30 -day postoperative mortality was $16 \%$ (18 patients) and was associated with high comorbidity (i.e., ASA score $\geq 3$ ) and older age. Death of a patient is classified as grade $\mathrm{V}$, according to the Dindo-Clavien criteria. ${ }^{17}$ Cause of death was not confirmed by autopsy in every case, but sepsis, usually in combination with multiorgan failure, was the most frequent cause (at least seven (50\%) of deaths). Other causes included myocardial infarction and renal and respiratory failures. No significant association between postoperative mortality and surgical approach was found (Table 2).

Shock and/or syncope at admission were more commonly encountered in patients with a duodenal perforation $(7 / 32 ; 22 \%)$ as compared to those with other ulcer localization $(13 / 82 ; 16 \%)$, but this difference was not statistically significant. Postoperative complications were recorded in 55 patients (49\%). Most of these patients had more than one complication, which included respiratory failure in $29(25 \%)$ patients, postoperative intra-abdominal infection in $18(16 \%)$ patients, cardiovascular events in $17(15 \%)$ patients, renal failure in 14 $(12 \%)$ patients, postoperative suture leakage in $10(9 \%)$ patients, wound infection in $6(5 \%)$ patients, postoperative bleeding in $2(2 \%)$ patients, and various other complications in $10(9 \%)$ of the patients. In addition, 16 patients $(14 \%)$ received treatment for suggested clinical sepsis. While the Dindo-Clavien grade I-II complications are treated without any physical interventions, the grade III complications require surgical, endoscopic, or radiological intervention. Grade IV complications are life-threatening, including single or multiorgan dysfunction. ${ }^{17}$ Among the 56 patients recorded with complications, $8(14 \%)$ patients had grade II, 10 patients (18\%) had grade III, 20 patients $(36 \%)$ had grade IV, and the 18 patients (32\%) who died were classified as grade $\mathrm{V}$.

In 13 patients $(11 \%)$, re-admittance to the hospital within 3 weeks after discharge was encountered. Causes for readmittance were pneumonia $(n=3)$, subphrenic abscess $(n=1)$, wound infection $(n=2)$, and deterioration of concomitant diseases $(n=7)$ including lung cancer, brain cancer, nonHodgkin lymphoma, and cardiovascular disease.

We compared patients' characteristics and outcomes according to type of surgical approach (Table 2). Age and gender distributions were similar, as were ASA and Boey scores (Table 2). No significant differences were observed with regard to preoperative delay and ulcer localization. The median duration of operation was shorter in the laparotomy group compared to the groups treated laparoscopically or the group of converted operations $(p=0.017)$. There was a nonsignificant difference with regard to postoperative complications, with more complications encountered in the laparotomy group $(p=0.057)$. However, the proportions of complications categorized according to
Fig. 2 Distribution of surgical approaches during the study period

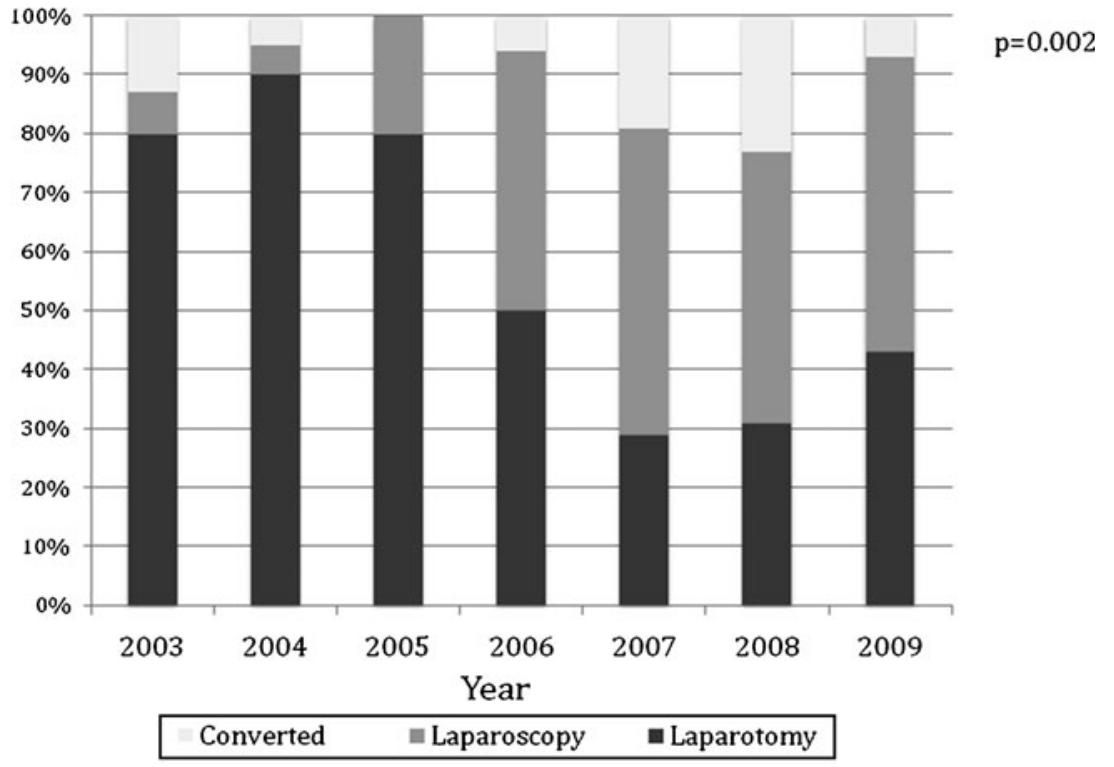


Table 2 Characteristics and outcomes according to surgical approach $(n=114)$

\begin{tabular}{|c|c|c|c|c|}
\hline Variable & Laparotomy 66 (58\%) & Laparoscopy 36 (32\%) & Converted $12(11 \%)$ & $p$ value \\
\hline Females & $37(56 \%)$ & $25(69 \%)$ & $5(42 \%)$ & $0.18^{\mathrm{a}}$ \\
\hline Median age [years] (range) & $71(20-100)$ & $62(29-95)$ & $65(40-87)$ & $0.16^{\mathrm{b}}$ \\
\hline \multicolumn{5}{|l|}{ ASA score } \\
\hline I & 0 & 0 & 0 & \multirow[t]{5}{*}{$0.69^{\mathrm{a}}$} \\
\hline II & $1(1 \%)$ & $1(3 \%)$ & 0 & \\
\hline III & $38(58 \%)$ & $26(72 \%)$ & $7(58 \%)$ & \\
\hline IV & $25(38 \%)$ & $8(22 \%)$ & $4(33 \%)$ & \\
\hline $\mathrm{V}$ & $2(3 \%)$ & $1(3 \%)$ & $1(9 \%)$ & \\
\hline \multicolumn{5}{|l|}{ Boey score } \\
\hline 0 & $12(18 \%)$ & $10(28 \%)$ & $4(33 \%)$ & \multirow[t]{4}{*}{$0.33^{\mathrm{a}}$} \\
\hline 1 & $33(50 \%)$ & $21(58 \%)$ & $4(33 \%)$ & \\
\hline 2 & $17(26 \%)$ & $4(11 \%)$ & $4(33 \%)$ & \\
\hline 3 & $4(6 \%)$ & $1(3 \%)$ & 0 & \\
\hline Preoperative delay $[\mathrm{h}]$ (median, range) & $6.6(1.4-116)$ & $5.8(1.8-113)$ & $6.0(3.3-50)$ & $0.5^{\mathrm{b}}$ \\
\hline \multicolumn{5}{|l|}{ Localization of perforation } \\
\hline Gastric & $34(52 \%)$ & $17(47 \%)$ & $7(58 \%)$ & \multirow[t]{4}{*}{$0.72^{\mathrm{a}}$} \\
\hline Pyloric & $6(9 \%)$ & $7(19 \%)$ & $2(17 \%)$ & \\
\hline Duodenal & $19(29 \%)$ & $11(31 \%)$ & $2(17 \%)$ & \\
\hline Not specified & $7(11 \%)$ & $1(3 \%)$ & $1(8 \%)$ & \\
\hline Median operative duration[min] (range) & $70(39-291)$ & $82(37-160)$ & $105(60-155)$ & $0.017^{\mathrm{b}}$ \\
\hline Postoperative complications & $38(66 \%)$ & $12(36 \%)$ & $5(12 \%)$ & $0.057^{\mathrm{a}}$ \\
\hline \multicolumn{5}{|c|}{ Complications according to Dindo-Clavien ${ }^{17}$ score } \\
\hline Grade I & 0 & 0 & 0 & \multirow[t]{5}{*}{$0.30^{\mathrm{a}}$} \\
\hline Grade II & $7(11 \%)$ & $1(3 \%)$ & 0 & \\
\hline Grade III & $5(8 \%)$ & $4(11 \%)$ & $1(8 \%)$ & \\
\hline Grade IV & $13(20 \%)$ & $6(17 \%)$ & $3(25 \%)$ & \\
\hline Grade V & $14(21 \%)$ & $3(8 \%)$ & $1(8 \%)$ & \\
\hline Postoperative mortality ( $\leq 30$ day) & $14(21 \%)$ & $3(8 \%)$ & $1(8 \%)$ & $0.18^{\mathrm{a}}$ \\
\hline
\end{tabular}

${ }^{\mathrm{a}}$ Chi-square test

${ }^{\mathrm{b}}$ Kruskal-Wallis test

the Dindo-Clavien criteria ${ }^{17}$ had a similar distribution within each group.

\section{Discussion}

Surgical treatment for perforated ulcer has changed during the last three decades, and duodenoraphy or gastroraphy with omentoplasty have more or less replaced gastric resection as emergency operations. ${ }^{18,19}$ Furthermore, a decrease in surgical trauma with the use of laparotomy for these often fragile patients is suggested to be of importance. However, others propose a laparoscopic approach is beneficial for low-risk patients in particular. ${ }^{13}$

While early studies were hampered by various shortcomings, including patient selection bias, study design, and low statistical power, a recent Cochrane report concludes that results from laparoscopic surgery are not clinically different from those of open surgery. ${ }^{14}$ Nevertheless, implementation of the laparoscopic approach for the treatment of patients with PPU has evolved rather slowly and is still not available around the clock in many surgical departments. ${ }^{15}$ This surgical emergency is commonly treated at local hospitals. Given the rather low number of cases, as indicated by our observed annual incidence of 5 per 100,000, it is difficult for all surgeons to gain the necessary technical experience.

This population-based study on consecutive patients confirms that perforation still remains a serious complication of peptic ulcer disease. However, the observed 30-day postoperative mortality of $16 \%$ is lower than the $25 \%$ mortality reported recently from Denmark, ${ }^{15}$ and the complication rate of $48 \%$ is comparable to other reports. Nevertheless, these data should be interpreted in the light of the advanced age and the general comorbidity of this population requiring surgical treatment for a potentially life-threatening condition. 
The observed postoperative mortality of $8 \%$ in the laparoscopically treated patients is in concordance with recent reports. ${ }^{15,20-23}$ Of note is the high proportion of patients, between $45 \%$ and $50 \%$, treated laparoscopically during the last 4 years of the study period. This is in contrast to recent figures reported from another Scandinavian population, which showed that only $6 \%$ patients were treated laparoscopically, and only half of the departments responsible for acute abdominal surgery offered laparoscopic repair of perforated peptic ulceration. ${ }^{15}$ In spite of a significantly larger proportion of laparoscopic completed procedures during the second half of the study period, our average conversion rate of $25 \%$ decreased to $12 \%$ during the last 3 years of the study period, which corresponds well with recent papers. ${ }^{12,13,24,25}$

Several risk factors, as mirrored by the Boey score, ${ }^{16}$ are of importance for interpretation of our results. Of note, these risk factors are, in most patients, determined during the pre-hospital time period from symptom onset to hospital admittance. Yet, an effective diagnostic work-up that could prompt urgent surgical treatment is of importance. Thus, appropriate clinical decision making should not be delayed by suboptimal imaging. This study also showed that plain abdominal imaging harbors a substantial risk for false negative results. Accordingly, when imaging is used, low-dosage CT should be preferred in this clinical situation. ${ }^{26,27}$

Similar to previous reports, there is a significant proportion of elderly patients with high comorbidity. ${ }^{6,20,28,29}$ The importance of an urgent diagnosis and appropriate surgical treatment in this fragile group of patients has been emphasized by others. ${ }^{28,30}$ The preoperative in-hospital waiting times experienced by most of our patients are in line with other authors. ${ }^{6}$

Although applied in a few single patients with PPU before 2004, since 2005, we have intended to use a laparoscopic approach for surgical treatment of patients with PPU when this technique was available among the responsible surgeons. ${ }^{13,14,23,31}$ Thus, we observed a significantly higher proportion of patients treated laparoscopically during the last part of the study period. Other studies have found less postoperative pain, shorter hospital stay, fewer septic events, and reduced wound infection with laparoscopy. ${ }^{32}$

Similar to the recent report by Møller et al., ${ }^{30}$ we observed a higher median age and significantly more comorbidities in females. This may partly be explained by a higher proportion of elderly females in our population, with high comorbidity closely relating to older age.

Gastric ulcer perforations, frequently associated with smoking in patients $<75$ years of age, were most commonly encountered, as previously reported by Svanes and coworkers. ${ }^{6}$

\section{Conclusions}

Data from the present study indicate that laparoscopic surgical treatment of patients with peptic ulcer perforation can be implemented and completed safely in a large proportion of patients with this life-threatening condition, given that the responsible surgical team has the appropriate technical expertise. Observations made in this study do not allow firm conclusions as to which patients should be selected for open versus laparoscopic treatment. The laparoscopic treatment of these patients may offer advantages in line with mini-invasive procedures for other conditions. It remains to be shown if promising figures reported from controlled trials can be achieved in the general surgical practice.

Open Access This article is distributed under the terms of the Creative Commons Attribution Noncommercial License which permits any noncommercial use, distribution, and reproduction in any medium, provided the original author(s) and source are credited.

\section{References}

1. Yeomans ND. Overview of 50 years' progress in upper gastrointestinal diseases. J Gastroenterol Hepatol. 2009;24 Suppl 3:S2-4.

2. Quenot JP, Thiery N, Barbar S. When should stress ulcer prophylaxis be used in the ICU? Curr Opin Crit Care. 2009;15(2):139-43.

3. Malfertheiner P, Chan FK, McColl KE. Peptic ulcer disease. Lancet. 2009; 374(9699):1449-61.

4. Bertleff MJ, Lange JF. Perforated Peptic Ulcer Disease: A Review of History and Treatment. Dig Surg. 2010;27(3):161-9.

5. Møller MH, Adamsen S, Wojdemann M, Møller AM. Perforated peptic ulcer: how to improve outcome? Scand J Gastroenterol. 2009;44(1):15-22.

6. Svanes C. Trends in perforated peptic ulcer: incidence, etiology, treatment, and prognosis. World J Surg. 2000;24(3):277-83.

7. Nathanson LK, Easter DW, Cuschieri A. Laparoscopic repair/ peritoneal toilet of perforated duodenal ulcer. Surg Endosc. 1990;4(4):232-3.

8. Lau WY, Leung KL, Zhu XL, Lam YH, Chung SC, Li AK. Laparoscopic repair of perforated peptic ulcer. Br J Surg. 1995;82 (6):814-6.

9. Stuart RC, Chung SC. Laparoscopic Repair of Perforated Peptic Ulcer. Semin Laparosc Surg. 1994;1(3):182-9.

10. Matsuda M, Nishiyama $M$, Hanai $T$, Saeki $S$, Watanabe $T$. Laparoscopic omental patch repair for perforated peptic ulcer. Ann Surg. 1995;221(3):236-40.

11. Lau WY, Leung KL, Kwong KH, Davey IC, Robertson C, Dawson JJ, et al. A randomized study comparing laparoscopic versus open repair of perforated peptic ulcer using suture or sutureless technique. Ann Surg. 1996;224(2):131-8.

12. Lau H. Laparoscopic repair of perforated peptic ulcer: a metaanalysis. Surg Endosc. 2004;18(7):1013-21.

13. Lunevicius R, Morkevicius M. Systematic review comparing laparoscopic and open repair for perforated peptic ulcer. Br J Surg. 2005;92(10):1195-207.

14. Sanabria AE, Morales CH, Villegas MI. Laparoscopic repair for perforated peptic ulcer disease. Cochrane Database Syst Rev. 2005 (4):CD004778. 
15. Sommer T, Elbroend H, Friis-Andersen H. Laparoscopic repair of perforated ulcer in Western Denmark - a retrospective study. Scand J Surg. 2010;99:119-21.

16. Boey J, Wong J. Perforated duodenal ulcers. World J Surg. 1987;11(3):319-24.

17. Dindo D, Demartines N, Clavien PA. Classification of surgical complications: a new proposal with evaluation in a cohort of 6336 patients and results of a survey. Ann Surg. 2004;240(2):205-13.

18. Paimela H, Oksala NK, Kivilaakso E. Surgery for peptic ulcer today. A study on the incidence, methods and mortality in surgery for peptic ulcer in Finland between 1987 and 1999. Dig Surg. 2004;21(3):185-91.

19. Wang YR, Richter JE, Dempsey DT. Trends and outcomes of hospitalizations for peptic ulcer disease in the United States, 1993 to 2006. Ann Surg. 2010;251(1):51-8.

20. Lohsiriwat V, Prapasrivorakul S, Lohsiriwat D. Perforated peptic ulcer: clinical presentation, surgical outcomes, and the accuracy of the Boey scoring system in predicting postoperative morbidity and mortality. World J Surg. 2009;33(1):80-5.

21. Rahman MM, Islam MS, Flora S, Akhter SF, Hossain S, Karim F, Mortality in perforated peptic ulcer patients after selective management of stratified poor risk cases. World J Surg. 2007;31 (12):2341-4.

22. Ates M, Sevil S, Bakircioglu E, Colak C. Laparoscopic repair of peptic ulcer perforation without omental patch versus conventional open repair. J Laparoendosc Adv Surg Tech A. 2007;17(5):615-9.

23. Siu WT, Chau CH, Law BK, Tang CN, Ha PY, Li MK. Routine use of laparoscopic repair for perforated peptic ulcer. Br J Surg. 2004;91(4):481-4.
24. Bertleff MJ, Lange JF. Laparoscopic correction of perforated peptic ulcer: first choice? A review of literature. Surg Endosc. 2010;24(6):1231-9.

25. Lee FY, Leung KL, Lai PB, Lau JW. Selection of patients for laparoscopic repair of perforated peptic ulcer. Br J Surg. 2001;88 (1):133-6.

26. Furukawa A, Sakoda M, Yamasaki M, Kono N, Tanaka T, Nitta $\mathrm{N}$, et al. Gastrointestinal tract perforation: CT diagnosis of presence, site, and cause. Abdom Imaging. 2005;30(5):524-34.

27. Hainaux B, Agneessens E, Bertinotti R, De Maertelaer V, Rubesova E, Capelluto E, et al. Accuracy of MDCT in predicting site of gastrointestinal tract perforation. AJR Am J Roentgenol. 2006;187(5):1179-83.

28. Makela JT, Kiviniemi H, Ohtonen P, Laitinen SO. Factors that predict morbidity and mortality in patients with perforated peptic ulcers. Eur J Surg. 2002;168(8-9):446-51.

29. Møller MH, Shah K, Bendix J, Jensen AG, Zimmermann-Nielsen E, Adamsen $\mathrm{S}$, et al. Risk factors in patients surgically treated for peptic ulcer perforation. Scand J Gastroenterol. 2009;44(2):145-52.

30. Møller MH, Adamsen S, Thomsen RW, Moller AM. Preoperative prognostic factors for mortality in peptic ulcer perforation: a systematic review. Scand J Gastroenterol. 2010;45(7-8):785-805.

31. Lam CM, Yuen AW, Chik B, Wai AC, Fan ST. Laparoscopic surgery for common surgical emergencies: a population-based study. Surg Endosc. 2005;19(6):774-9.

32. Bertleff MJ, Halm JA, Bemelman WA, van der Ham AC, van der Harst E, Oei HI, et al. Randomized clinical trial of laparoscopic versus open repair of the perforated peptic ulcer: the LAMA Trial. World J Surg. 2009;33(7):1368-73. 